\title{
Research on the Opening of Government Data in Government Governance Reform in the Era of Big Data*
}

\author{
Yan Yang \\ School of Information Management \\ Nanjing University \\ Nanjing, China 210093 \\ School of Political and Public Administration \\ Yunnan Nationality University \\ Kunming, China 650091
}

\begin{abstract}
Big data brings all aspects of governance reform, opening a new era of transformation. Government governance in big data era has the following characteristics: data governance, multi-governance, flat governance and so on. The new features of government governance have promoted the government data liberalization movement. To big data government, open government as the goal, to promote the government's open sharing of data resources, is conducive to creating a new model of precise governance, multi-party collaboration of social governance, and enhance government governance capabilities. Government data liberalization should follow the procedures of platform construction, data management and technological innovation. At present, the construction of data open standards, privacy issues, security issues and the construction of laws and regulations are urgent concerns in the process of opening of the government data.
\end{abstract}

Keywords-government administration; big data; government data openness; governance capability

\section{INTRODUCTION}

With the increasing deepening of network and information application, the global data is growing explosively, so the influence of application of big data expands day by day and the wave of big data sweeps the world overwhelmingly. In the era of big data, the national competitiveness is partly reflected in the scale, activity and quality of data and the ability to explain and apply the data [1]. As the largest owner of data resources, how the government effectively controls, develops and utilizes data is related to the future development of a country and international competition. Among them, centering on the opening of the government data to promote the building of government governance capacity is an important issue for the reform on government governance in the era of big data.

In March 2012, the US government released the

*This paper is one of the research results of the school project of Yunnan Minzu University- "research on public digital culture management mechanism in Yunnan under the background of big data" (project number: 2016 QN07).
"Research and Development Program of Big Data" to raise the big data to national strategic level. In October 2015, the State Council promulgated the "Scheme for the Promotion of Big Data Development" [2], which clearly puts forward to comprehensively promote the development and application of big data in China, strengthens the national overall management on data resources, and gives priority to open the data of relevant field. By 2018, we should build a unified open portal of national government data and promote the ability to open and share the data resources of government and public sector, so as to create a new social governance model of accurate management, multi-collaboration and enhance the capacity of government governance. Thus, government governance issue centering on the opening of government data becomes the focus of society.

\section{NEW FEATURES OF GOVERNMENT GOVERNANCE IN THE ERA OF BIG DATA}

Big data with massive data volume, variety of data type, great data value and fast processing speed and high Velocity [3] have led to an overall social reform, which not only results in technology revolution and economic revolution, but also leads to reform on national governance. Big data plays an important role in transforming the governance ideas of a country, reforming governance measures, optimizing governance processes and promoting modernization of national governance, which has become an important resource of national governance. The government governance in the era of big data shows the following new features:

\section{A. Data Governance}

In the traditional governance, relying solely on government to manage and protect the data leads the government suffer from the large-scale and complex data. In the era of big data, the data is not only large in its capacity, but also large in its "great value" [4]. For governments with large, valuable and reliable data, the value of large data is reflected in at least two aspects: first is the "new knowledge", 
which means we can acquire valuable information timely through rapid and efficient process of massive, dynamic, diversified, high-growth, and efficient data; second is the "new results", which refers to the new results acquired through the opening of data, acquisition of related data and the use of data mining and knowledge association analysis technology can be directly applied to the process of government governance to improve the ability of government governance. It can be said that big data is opening up a major transformation of era.

\section{B. Multi-governance}

The traditional governance takes the country and the government as the main body since the government holds a large number of available resources while the public are passive recipients of decision-making. With the development of Internet, proposing of the open government and transparent government, active participation of some social organizations, business organizations and social citizens in government management, the national governance structure gradually turns to multiple governance. Especially in fields of public services including public transport, health, food safety, environmental management and emergency management, market organizations and social organizations begin to play an active role in governance. At the same time, under the background of big data, the modernization of national governance also needs the diversification of governance subjects and tools. The cooperative management of multiple subjects like sovereign owners, managers and stakeholders in social public affairs will help to promote public interest and maintain public order [5].

\section{Open Governance}

In the traditional governance mode, the government has a comprehensive grasp of governance information and functional departments grasp the information of relevant industry, forming information islands unrelated with each other between different departments. Government is the only information publisher, leading the government too busy to attend to the large-scale and complex data and thus information gained by the public is often incomplete, not timely and updated slowly. In the era of big data, big data are widely distributed in the government, enterprises, social organizations and individuals. Impact of information technology such as big data, cloud computing, socialization, network multi-media and so on breaks the monopoly of government in information data, so that the network giants, commercial companies, social organizations and even the general public have mastered a lot of data and the differences of information, knowledge and time that originally exist in the government and the public, enterprises, and all kinds of organizations gradually eliminate. The closed structure with government as the core is challenged and the national governance structure gradually becomes open.

\section{Flat Governance}

In the era of large data, popularization of information technology makes data sharing, department cooperation and joint decision-making within the government become possible. The gap between departments is flattened, so the traditional bureaucratic class structure is no longer adaptable to the requirements of modern social development and the national governance structure began to turn to flat structure. The public began to participate in social governance through mobile phones, tablets and other electronic equipment and the network we media, challenging power of the traditional government decision. Hence, transparent, efficient and responsible government has become the goal of government reform, which means the country plays the function of "steering" while decision-making and discussion are mostly made by the market and society and public decision-making mechanism becomes inevitable.

\section{THE INEVITABILITY OF OPENING OF GOVERNMENT DATA IN GOVERNMENT GOVERNANCE}

Compared with enterprises, social organizations and the public, the government as the main manager and distributor of social resources, has the data with more types, wider scope, greater time span, higher reliability and greater value. The opening of the government data firstly originated in the Western developed countries, since the history of data open and that of its public management revolution of domestic government coincide with each other, which is the activity that government lead the society to achieve social innovation and public innovation[6]. The core point of the governance theory raised in the 1990s advocated managing public affairs through the partnership of cooperation and consultation. With the development of information technology, it hopes to change the state of bloated and inefficient government by managing information and reengineering the process through information technological revolution, which lead to the reform in diversification of subjects, network of structure, interaction of process and coordination of method. At present, many countries in the world are actively promoting the opening of government data. In light of the three phases theory of network development of web1.0 - web2.0 - web3.0, we can now call this round of new global government revolution promoted by big data, cloud computing and information revolution and based on the opening of government data the revolution of government 3.0. The government 3.0, first proposed by Korean government, taking the premise of big data government and open government focuses more on the active openness and sharing of government data based on the emphasis of government 2.0 of openness, synergy, and user-centered government, and with the help of the mining, analyzing and intelligent processing ability of big data mining, it reconstruct the government processes, build a transparent, responsible and efficient government and enhance governance capacity of government [7]. In the era of big data, the inevitability of opening of government data in the reform of government governance is mainly reflected in the following aspects:

\section{A. Intelligent Application of Government Data Management}

In the ear of big data, advanced data analysis technology based on data mining, machine learning and intelligent analysis promote the transformation of data to knowledge 
and extensive application of data. Collection, analysis, management and utilization of data have become the top priority for the research on network information technology. As the owner of the wealth in data age, how to give play to the vitality of the large number of key data in hands is the key issue of government in the era of "big data". Among them, promoting the opening of government information by using the latest technology based on the information technology leads to a new era of open government. With the rise of e-government, government of each country has launched the information disclosure program in network age. In 2009, the US federal government announced to implement the "open government plan." "Platform for the promoting the development of big data" issued by China's State Council makes it clear that by 2018 , it will construct the unified portal of national government data to promote the unification of data resources from the government and public sector and open to the society together[2]. In the era of big data, with the help of the Web 3.0 technology represented by Semantic Web, the government can communicates with the public in real time by posting information through government websites and mobile terminal equipment. The information technology is used to analyze and semantics associate the large number of real-time data on line to fully dig the value of government data resources, form accurate reports, and support official statistics, research data and warning system to generate information, and achieve value-added information, which can provide better services for government.

\section{B. Multi-party Cooperation in Government Governance}

The society in the era of big data is a netty and more open society. With the popularity of the Internet and pervasive computing, it is difficult for the government to prevent the pace of history of data open and the two-way transmission of information [8]. Data open has become a trend. With the rapid development of wireless networks, wide application of mobile phones, tablet, other intelligent terminals, and sensors, and rise of the network we-media like WeChat and microblog, release and dissemination of information go beyond the constraints of time and space and data open and public information sharing become a necessity, so more and more people join the activity of "open government" and "open society". The government governance in the era of big data needs to center on the data and resort to the information technology, to achieve public participation and open and common decision-making social governance model. In this context, as the providers of social management and public service, the government needs to keep up with the pace of the times, to let the public, civil society organizations, enterprises participate in the development and utilization of data resources based on opening of government data, so that they can actively know the government work, find the demand, and actively participate in decision-making, improve the level of government decision-making and pertinence of policies, and enhance the social management level of government.

\section{Personalization of Government Public Services}

The semantic network in future will be a highly personalized intelligent network platform, and personalized service has become an important feature of information service in the era of big data. It uses the business intelligence analysis technology to achieve high degree of segmentation and precise positioning and data mining technology to achieve model prediction, so as to customize for the users to provide a highly personalized information services. Because of the convenience of information acquisition and the public demand for government information acquisition, the government publicizes government information through the government portal, government microblog, WeChat official account, and mobile government and so on and uses data mining tools to intelligently associate and analyze the large number of real-time data of browsing status of the public on government website including the times of browsing, column attention, online application services, network reviews and other activities, and thus generates an accurate analysis reports, provides personalized services, promotes business innovation, meets the public's demand and improve the government's ability to govern.

\section{PROCEDURES AND CONTENT OF OPENING OF GOVERNMENT DATA}

In the practical case, the United States, taking opening of government data as a precursor, encourages all kinds of social actors to participate and use government data, to achieve the improvement of government public services, and strengthen the supervision on the government. Since more and more countries or governments are aware of the many benefits of data open, they join the process of "open government" and "open society". In 2009, the US government data portal Data.gov came online. On Sep. 20th in 2011, eight countries including the United States, Britain, Brazil, Indonesia, Mexico, Norway, the Philippines, and South Africa jointly signed the "open data statement", to establish the open government partners (OGP, Open Government Partnership). In November 2011, the EU explicitly proposed an open data strategy, followed by the establishment of the European Open Data Portal, which provides public with the access to public data of the European Commission and other EU agencies. In June 2013, heads of the eight states including the United States, Britain, France, Germany, Japan, Canada, Italy and Russia signed the Open Data Charter at the Northern Ireland summit and pledged to further open the machine readable government data to the public in accordance with the Charter and Technical Annex Open at least by the end of 2015.

During the implementation, how to open and what areas of government data to give priority become the key point of thinking.

\section{A. Procedures for Opening of Government Data}

In order to better promote and improve the opening of government data, we should establish the basic procedures for opening of government data. Big data is not just a technological revolution, but also a revolution of concept, so 
the success of opening of government data needs to have the basis of politics, law and organizational management. Therefore, the first step is to make a good policy planning. That is accomplishing top design from the national level, strengthening the construction of management structure and institutional mechanisms, and establishing a special government department in charge of government data open project. Based on this, they should set clear data open system, goals and forward direction, establish the strategic plan for government data and open timetable, to carry out data open plan step by step.

The second step is to build the basic platform. The opening of government data in the era of big data emphasizes the importance of using information technology and networks. The opening of government data based on network is the basis for the opening of government data in the era of big data. Therefore, it is necessary to establish a national information infrastructure and an open platform and set up a national data portal to ensure that all data sets are published through the unified data portal.

Step three is data Management. We should establish a data collection network to ensure the quality of data, and classify and organize the valuable data on this basis to organize them in standardized format, form data sets, and update them according to new situation and new problems in real time. On this basis, with information technology as the support point, we should regularly open the government data to the public through the data open portal, to publicize data open situation of the whole society, and create ecological environment and industrial chain of data open, so that sharing of a wider range of government data, public data, enterprise data can be achieved, data barriers can be broken, and data islands can be eliminated. At the same time, we can achieve data reproduction, data value re-use, rolling to create value through data aggregation, data association, data discovery and other technologies. We can learn from the international experience, to open non-confidential high-value data sets firstly. At the meantime, we need to improve the open data policy through the solicitation of public and social opinions combining with actual situation in China, and make clear which data should be given priority to publicize. In the process of data open, data acquisition threshold should be reduced, to promote open and effective evaluation interaction, and accept social supervision. In addition, private capital and institutions are encouraged to participate in data sharing.

Finally is the implementation of technological innovation. We should build an open platform drawn by application, to encourage to support the innovators for domestic and foreign data open by sharing experience and tools, continue to support the research, development and integration of relevant key technology, construction of big data platform, data open and demonstration applications, and encourage the innovation of social secondary development and application model while constantly improve the development environment and raise the data transparency. Thus we can promote the sustained, healthy and standardized development of opening of government data.

\section{B. The Open Scope of Government Data}

Judging from the open history of Western countries, people's livelihood needs and public value is the starting point and main concern of government data open [6]. At present, more than 130 countries have gradually carried out the opening and sharing of government data, and formulate directory set of data open especially in the fields of education, medical treatment, environment, health, environmental protection, meteorology, social welfare, public transportation, labor resources and other public services.

In the Data Open Charter, 14 kinds of high-value data are given priority, including enterprise/ company registration information and other enterprise data; crime statistics, public safety and other judicial data; school performance, digital ability and other education data; pollution levels, energy consumption and other energy and environment data; earth observation data of meteorology / weather, agriculture, forestry, animal husbandry and fishery; financial data such as financial budget and government procurement and so on; terrain maps, postal codes and other geospatial data; census, infrastructure and other statistical data; foreign aid, food safety and other global development data; genomics, research and development and other scientific data.

Combining with the plan for opening of government data in other countries and regions, it can be seen that opening of government data, needs to set the security baseline, which means don't open the major confidential information involving national security and information security. For the government data that can be open, we should formulate the overall planning and sector planning for opening of national data and data open list. Opening of data should be started from focusing on people's livelihood, which means to give priority to the data of fields concerned by people including government expenditure, transportation, education, health, labor, environment and social welfare and so on and the public big data that can promote social innovation and public management innovation.

\section{PROBLEMS RELATED TO OPENING OF GOVERNMENT DATA AND ITS COUNTERMEASURES}

Big data will pose a great challenge to the traditional state governance pattern, remodel the empowerment relation and governance structure of the state and society, and form a pluralistic and open governance structure, so the opening of government data becomes the inevitable choice of the era. Nevertheless, data open is only a starting point since the merely opening of data is not enough and the relevant technical standards, data open standards, privacy issues, security issues, and laws and regulations at this stage has not been resolved, we need to proceed from the national level, to plan the issues related to data open.

\section{A. Formulate Data Standards}

It can ensure the interconnection of data and achieve cosharing of resources to formulate big data standards, unify the standards of data encoding, processing, sharing, exchanging and form standard data, which is conducive to the eliminate the data islands. Since 2012, ITU-T, ISO / IEC, 
NIST and other foreign standardization organizations have set up working groups in succession to carry out the development work of data open standards. Currently, the systematic frame of big data standards is mainly constructed from the aspects of basics, products, application, and technology. China also actively promoted the construction of data open standards over the past two years. By the end of 2014, the National Information Technology Standardization Technical Committee set up big data working group, and then began to overall launch the standardization work of big data in China. At present, technical standardization has made some progress, but standards for data analysis, data security, data services and other aspects have not yet been established. At the same time, taking the international open data standardization into account, there is no data standards consensus established at the global level. Therefore, it is the direction of the data standard to strengthen the cooperation of data standards internationalization, establish international data standards, improve the general principles of data standards and refine the data standard rules.

\section{B. Pay Attention to Protection for Data Privacy}

Privacy, the sensitive information that one party don't want others to know or is inconvenient to known, is a kind of personal interest, which has nothing to do with the public interest or group interests and has the characteristics of hiddenness. [10] With the development of network technology, individuals form a large number of usergenerated data and business data, making the collection of personal information easier, so it is more and more difficult for individual users to prevent their personal information from collecting, storing, utilizing or even selling. In the era of big data, the connotation and extension of traditional privacy data has been expanded and broken through. The panic caused by the failure to protect privacy data is more harmful and privacy data protection faces more challenges. In addition to technology, management and law, the data may also involve morality, ethic, business interests, lifestyle and behavior habits and so on; not only individuals or groups, it may also involve national security and international order. In addition, data opening and sharing actually causes the contradiction between encryption and validity of data [1], which needs the consideration of making a best compromise between data open and protection for user privacy. Therefore, the privacy issues need to be solved by joint effort from technology, legislation, morality and other aspects.

\section{Strengthen Data Security}

Information security refers to protecting computer-related hardware and software and data from damaging, changing or exposing due to accidental or malicious reasons by adopting necessary technical and management tools [11]. The security issues in the era of big data are more complex than traditional security: centralized storage of large amounts of data increases the risk of data leakage; data open brings challenges to integrity, availability, and secrecy of data; technology of data mining and analyzing requires to fully explore the data value, which may also lead hackers to use big data analysis for network attacks. In addition, there are many cross-border transactions of data in the network era, such as the global e-commerce Alibaba, of which the large number of user data are related to data sovereignty, and even national information security, which needs to be considered in the top design of national data open. The goal of opening of government data in the era of big data is to promote the optimization of government governance, of which the goal is to safeguard national security, promote social development and economic prosperity, promote public interest, maintain public order and achieve social justice [12]. Therefore, data security is not just information security, technical security and network security, but it has risen to the level of national strategic security to a large extent. In 2013, with exposure of "prism door" incident in the United States, the US government introduced a series of network security strategy including national strategy for cyberspace and network international action planning, marking the United States began to establish the data hegemony in network era. In 2015, the European "security framework for government cloud procurement" was released to put forward a complete system for the aspects of risk forecasting, secure target structure and cloud procurement of the public institutions of governments. Since then, Japan and other countries have also introduced the data security strategy in network era successively. In the new round of strategy competition of big data, opening of government data in China is only in the experimental stage. Nonetheless, we should make plan for the issues of data security and cross-border data sovereignty management issues from the beginning, to establish advanced international strategic defense system for big data.

\section{Enact Relevant Laws and Regulations}

Planning and practice of data open need to be fixed in the form of laws and regulations, so that big data can truly become a tool for social welfare, rather than the channels for breeding privileges of politics, economy and society [13]. The United States and many countries in the Europe have established laws related to the opening of government information in the last century. Such as "Freedom of Information Act", "Electronic Freedom of Information Act", "Data Quality Law", "Open Government Law" and so on introduced by the US government, based on emphasizing protection for the privacy rights and right to know, they made more detailed and clearer provisions for the scope of data open. China's government passed the "Open Government Information Regulation" in June 2008, but compared with developed countries, data sharing laws and regulations in China are not perfect. The existing relevant laws and regulations lack legal effect in the actual operation, which need us to further strengthen the legal system construction and publicity. In regard to the data privacy laws and regulations, those of European countries are relatively sound. For example, the European Union promulgated the "EU Data Protection Directive" in 1995 , Germany passed the "Information and Communication Services Act" in 1997 for dealing with protection for the personal data of telecommunications industry, and the United Kingdom promulgated the "Data Protection Act" in 1998 to prohibit the sale of personal data without permission. At present, there is no special law on personal privacy protection, only with some scattered provisions in the "Constitution", 
"General Principles of Civil Law", "Protection Measures of International Network Security in Computer Information Network", "Telecommunications Regulations of People's Republic of China ", and "Network Security Law of People's Republic of China".

\section{CONCLUSION}

In the era of big data, opening of government data is the inevitable choice to promote the participation of various social subjects in government governance, strengthen the supervision on government, improve the capacity of government's governance and realize social governance. Opening of Government data needs to be considered on the national strategic level, and the related systems, technology, procedures, methods need joint participation and research of government departments, circles of business and academia, and the public. In practice, we are required to base on considering security and freedom, national security and personal privacy, personalized services and national interests, to establish a sound laws and regulations, form a long-term effective mechanism, and mine the huge social value from the data sharing and opening, and ultimately promote the construction of capacity of efficient, transparent and open government governance.

\section{REFERENCES}

[1] China Computer Federation big data expert committee. White Paper on Big Data Technology and Industry Development in China [201604-

12].http://wenku.baidu.com/view/10cfd54efad6195f312ba689.html?fr om=search.

[2] An Bei, Zhao Chao. China will complete unified open portal of national government data by 2018 years of. [EB/OL]. [2016-10-07]. http://politics.people.com.cn/n/2015/1007/c100127668864.html.

[3] Mckinsey Global Institute.Big Data:The bext frontier for innovation,competition, and productivity[EB/OL]. [2016-1020].http://www.doc88.com/p-667131489289.html.

[4] Liang Zhengming. Big Data Governance: the Righteousness of the Modernization of State Governance, Journal of Jishou University (Social Sciences Edition), 2015(3):34-41.

[5] He Zengke. On National Governance and Its Modernization, Journal of China National School of Administration, 2014(4):11-14.

[6] Big Data Digest. Zhang Monan: Data Open Promote the Transformation and reform of national governance. [EB/OL]. [201610-18].http://www.cbdio.com/BigData/201510/08/content_3926062.htm.

[7] China News. Park Geun-hye government 3.0 era of South Korea is officially launched, emphasizing the serving for people. [EB/OL]. [2016-10-20].http://www.chinanews.com/gj/2013/0619/4946345.shtml.

[8] Liu Yeting, Wang Chunxiao. "Big data", new action-- Analysis on the Change of Government action Mode in the Background of "Big Data" leadership science, 2012(12):4-6.

[9] China Economic Net. The four characteristics of the global government's data open. [EB/OL]. [2016-09-20]. http://intl.ce.cn/specials/zxgjzh/201402/20/t20140220_2343380.shtml.

[10] Blum,A.,et al. A learning theory approach to noninteractive database privacy[J]. J.ACM,2013,60(2):1-25.

[11] Bainbridge,W.S.Privacy and property on the net:Research questions[J].Science, 2013,302(5651):1686-1687.
[12] Wang Fang, Chen Feng. Research on the Utilization of Opening of Government big Data in the Process of National Governance China public administration, 2015(11):6-12.

[13] Wang Xiangmin. The Transformation of national governance in the era of big data. Exploration and Free Views, 2014(10):59-62. 